\title{
Analysis of the NTPDase and ecto-5'-nucleotidase profiles in serum-limited Trichomonas vaginalis
}

\author{
Amanda Piccoli Frasson', Mariele Feiffer Charão², Denis Broock Rosemberg³, \\ Ana Paula de Souza ${ }^{4}$, Solange Cristina Garcia ${ }^{2}$, Cristina Bonorino ${ }^{4}$, \\ Maurício Reis Bogo ${ }^{5}$, Geraldo Attilio De Carli ${ }^{6}$, Tiana Tasca ${ }^{1 /+}$
}

\footnotetext{
${ }^{1}$ Laboratório de Pesquisa em Parasitologia ${ }^{2}$ Laboratório de Toxicologia, Faculdade de Farmácia ${ }^{3}$ Departamento de Bioquímica Instituto de Ciências Básicas da Saúde, Universidade Federal do Rio Grande do Sul, Av. Ipiranga 2752, 90610-000

Porto Alegre, RS, Brasil ${ }^{4}$ Laboratório de Imunologia Celular e Molecular ${ }^{5}$ Laboratório de Biologia Genômica e Molecular

${ }^{6}$ Instituto de Geriatria e Gerontologia, Pontifícia Universidade Católica do Rio Grande do Sul, Porto Alegre, RS, Brasil
}

\begin{abstract}
Trichomonas vaginalis is a parasite of the human urogenital tract that causes trichomonosis, the most prevalent non-viral sexually transmitted disease. Ectonucleoside triphosphate diphosphohydrolase (NTPDase) family members, which hydrolyse extracellular ATP and ADP and ecto-5'-nucleotidase, which hydrolyses AMP, have been characterised in T. vaginalis. For trichomonad culture, the growth medium is supplemented with $10 \%$ serum, which is an important source of nutrients, such as adenosine. Here, we investigated the ATP metabolism of T. vaginalis trophozoites from long-term cultures and clinical isolates under limited bovine serum conditions (1\% serum). The specific enzymatic activities were expressed as nmol inorganic phosphate (Pi) released/min/mg protein, the gene expression patterns were determined by reverse transcriptase-polymerase chain reaction, the extracellular adenine nucleotide hydrolysis was analysed by high performance liquid chromatography and the cell cycle analysis was assessed by flow cytometry. Serum limitation led to the profound activation of NTPDase and ecto-5'-nucleotidase activities. Furthermore, the levels of NTPDase A and B transcripts increased and extracellular ATP metabolism was activated, which led to enhanced ATP hydrolysis and the formation of ADP and AMP. Moreover, the cell cycle was arrested at the G0/G1 stage, which suggested adenosine uptake. Our data suggest that under conditions of serum limitation, NTPDase and ecto-5'-nucleotidase play a role in providing the adenosine required for $\mathrm{T}$. vaginalis growth and that this process contributes to the establishment of parasitism.
\end{abstract}

Key words: Trichomonas vaginalis - serum limitation -

ectonucleoside triphosphate diphosphohydrolase - ecto-5'-nucleotidase - adenosine

Trichomonosis, which is caused by the flagellate protozoan Trichomonas vaginalis, is the most common non-viral sexually transmitted disease. There are an estimated 174 million new cases per year (WHO 2001) of trichomonosis. This infection has been associated with serious health consequences for women, including adverse pregnancy outcomes (Cotch et al. 1997), infertility (Goldstein et al. 1993), predisposition to cervical cancer (Viikki et al. 2000) and pelvic inflammatory disease (Cherpes et al. 2006). Trichomonosis in men is a recognised cause of urethritis, and complications such as prostatitis, epididymitis and infertility have been described (Johnston \& Mabey 2008). Moreover, the infection is a co-factor for human immunodeficiency virus transmission and acquisition (Van Der Pol et al. 2008). As the host-parasite relationship is very complex (Lehker \& Alderete 2000) and there is a broad range of clinical symptoms that can-

Financial support: CNPq (\#477348/2008-4 to TT), NANOBIOTECBrazil/CAPES

$\mathrm{APF}$ is the recipient of a fellowship from CNPq, DBR from CAPES, MFC from CAPES/REUNI.

+ Corresponding author: tiana.tasca@ufrgs.br

Received 6 May 2011

Accepted 9 August 2011 not be easily attributed to a single pathogenic mechanism, it is important to study the biochemical properties of this parasite to better understand these disease components.

Nucleotides, such as ATP, ADP and AMP and their nucleoside derivative, adenosine, are found in all animal organ systems and produce effects through both intracellular and extracellular mechanisms (Yegutkin 2008). Extracellular nucleotides and nucleosides are involved in diverse biological and pathological processes and their effects are mediated via a series of selective purinergic type 1 and type 2 receptors (Burnstock 2007, Sansom et al. 2008). Ectonucleotidases are a group of ectoenzymes involved in the control of nucleotide and nucleoside levels and can inactivate these molecules by hydrolysis. This group of enzymes includes the ectonucleoside triphosphate diphosphohydrolase (NTPDase) family that hydrolyses nucleoside tri and diphosphates, as well as the ecto-5'-nucleotidase that hydrolyses nucleoside monophosphates (Zimmermann 2001, Robson et al. 2006). Therefore, as T. vaginalis lacks de novo purine synthesis, the hydrolysis promoted by the ectonucleotidase cascade may provide the primary precursors of purine nucleotides for the parasite (Heyworth et al. 1982, Munagala \& Wang 2003). Previous studies from our group have characterised the NTPDase (Matos et al. 2001) and ecto-5'-nucleotidase (Tasca et al. 2003, 2005) activities in the trophozoites of $T$. vaginalis. 
In vivo bacterial autolysis and sloughed endometrial cells provide rich sources of purines and pyrimidines for $T$. vaginalis. The parasites have been shown to be phagocytic and the contribution of phagocytosis to nutrient acquisition is advantageous for the parasite, as the vaginal cavity can be a harsh environment with scarce nutrients (Pereira-Neves \& Benchimol 2007). In vitro, parasite culture medium is typically supplemented with bovine, horse or human serum to provide an important nutritional source for the trophozoites (Linstead 1990). In mammalian cells, it has been demonstrated that serum deprivation alters cellular growth and promotes an increase in the incorporation of adenosine into adenine nucleotides (Rapaport \& Zamecnik 1978). Considering that (i) trichomonads have no ability to perform de novo purine or pyrimidine synthesis and (ii) the serum added to the medium represents a source of nucleosides, we hypothesised that in a situation of nutrient (serum) limitation, the ectonucleotidases of $T$. vaginalis could provide the adenosine required for parasite growth. Therefore, the main goal of the present study was to evaluate the effect of bovine serum limitation on the NTPDase and ecto-5'-nucleotidase activities gene expression profiles and to investigate the effect of this condition on ATP metabolism and the T. vaginalis cell cycle.

\section{SUBJECTS, MATERIALS AND METHODS}

Culture of T. vaginalis - The T. vaginalis isolate 30236 (from the American Type Culture Collection) and TV-LACH1, a fresh clinical isolate (from the Clinical Laboratory, Faculty of Pharmacy, Federal University of Rio Grande do Sul, Brazil), were used in this study. Trichomonads were cultured axenically in vitro on trypticase yeast-extract maltose (TYM) medium ( $\mathrm{pH}$ 6.0) that was supplemented with $10 \%(\mathrm{v} / \mathrm{v})$ heat-inactivated bovine serum (HIBS) and incubated at $37^{\circ} \mathrm{C}( \pm 0.5)$ (Diamond 1957). Organisms in a logarithmic phase of growth exhibiting motility and a normal morphology were harvested. These were then centrifuged, washed three times with phosphate buffered saline (PBS) $1 \mathrm{x}$ and resuspended in new TYM medium for the following experiments.

Kinetic growth curve and serum limitation conditions - To investigate the influence of serum limitation on $T$. vaginalis growth, experiments to determine the kinetic growth curves were performed using both isolates. For these experiments, an initial inoculum of $1.0 \times 10^{5}$ trophozoites $/ \mathrm{mL}$ was grown in the presence of $1 \%(\mathrm{v} / \mathrm{v})$ HIBS on TYM medium. The results are expressed as the percentage of living organisms compared to the parasite control (10\% HIBS) and are representative of at least three independent experiments (using different cultures).

Following the kinetic growth curve analysis, trichomonads $\left(1.0 \times 10^{5}\right.$ trophozoites $\left./ \mathrm{mL}\right)$ of the ATCC 30236 isolate were placed in TYM medium supplemented with $1 \%$ HIBS for $2 \mathrm{~h}$, while the TV-LACH1 isolates were treated with this same condition for $24 \mathrm{~h}$.

Enzyme assays - Trophozoites were harvested and washed three times with $0.9 \%(\mathrm{w} / \mathrm{v}) \mathrm{NaCl}$ solution and the viability was evaluated using trypan blue $(0.2 \%)$ dye exclusion. The parasite suspension was diluted to a final protein concentration of approximately $0.6 \mathrm{mg} / \mathrm{mL}$ (ATCC 30236 isolate) or $0.4 \mathrm{mg} / \mathrm{mL}$ (TV-LACH1 isolate) to ensure linearity in the enzyme assays. Protein levels were measured with the Coomassie blue method (Bradford 1976) and bovine serum albumin was used as the standard.

Intact organisms were added to the NTPDase reaction mixture $(50 \mathrm{mM}$ Tris buffer, $\mathrm{pH} 7.2$ and $5.0 \mathrm{mM}$ $\mathrm{CaCl}_{2}$ ) to measure ATP and ADP hydrolysis (Matos et al. 2001). Parasites at the same density were added to the ecto-5'-nucleotidase reaction mixture $(50 \mathrm{mM}$ Tris buffer, $\mathrm{pH} 7.5$ and $3 \mathrm{mM} \mathrm{MgCl}$ ) (Tasca et al. 2003). The samples were preincubated for $5 \mathrm{~min}$ at $37^{\circ} \mathrm{C}$ in $200 \mu \mathrm{L}$ of the reaction mixture. The reaction was initiated by the addition of the ATP and ADP substrates (final concentration $1.0 \mathrm{mM}$ ) for the NTPDase assay or by the addition of AMP (final concentration $3.0 \mathrm{mM}$ ) for the ecto5 '-nucleotidase assay. The reaction was terminated by adding $200 \mu \mathrm{L}$ of $10 \%(\mathrm{v} / \mathrm{v})$ trichloroacetic acid (TCA). The samples were chilled on ice for $10 \mathrm{~min}$ before measurement of the release of inorganic phosphate $(\mathrm{Pi})$ was conducted (Chan et al. 1986). Intact organisms were added to the reaction mixtures containing TCA as a control to correct for non-enzymatic hydrolysis of the substrates and the average control values were subtracted from the test sample values. The specific activity was expressed as nmol Pi released $/ \mathrm{min} / \mathrm{mg}$ of protein. All samples were run in triplicate for at least three independent experiments (using different cultures).

Analysis of gene expression by reverse transcriptasepolymerase chain reaction (RT-PCR) assay - T. vaginalis gene expression patterns were evaluated using a semiquantitative RT-PCR assay. The NTPDase sequences were found using the BLAST function of the GenBank database and specific primers for NTPDase A and B were designed (Table) (Carlton et al. 2007).

After a period of serum limitation, $T$. vaginalis trophozoites were centrifuged and washed three times with PBS buffer ( $\mathrm{pH}$ 7.2) prior to total RNA extraction using the TRIzol reagent (Invitrogen, Carlsbad, CA, USA) in accordance with the manufacturer's instructions. The purity of the RNA was spectrophotometrically quantified by calculating the ratio between the absorbance values at 260 and $280 \mathrm{~nm}$. Next, cDNA species were synthesised from $2.0 \mu \mathrm{g}$ of total RNA using the SuperScript $^{\mathrm{TM}}$ III first-strand synthesis SuperMix (Invitrogen, Carlsbad, CA, USA) according to the supplier's instructions. The PCRs were performed in a volume of $20 \mu \mathrm{L}$, which included $0.1 \mu \mathrm{M}$ of the specific NTPDase primers, $2.5 \mathrm{mM} \mathrm{MgCl}_{2}$ and $0.5 \mathrm{U}$ Taq Platinum (Invitrogen, Carlsbad, CA, USA) in the supplied reaction buffer. The sequences of the $\alpha$-tubulin primers matched those from previously described data (Kucknoor et al. 2005) and the PCR conditions were performed in accordance with previous studies (Giordani et al. 2010, Rückert et al. 2010) using $0.5 \mathrm{M}$ betain. All of the assays were carried out using $1.0 \mu \mathrm{L}$ of the cDNA template. The PCR conditions for the NTPDase reaction were as follows: there was an initial 1 min denaturation step at $94^{\circ} \mathrm{C}$, a 1 min annealing step (NTPDase A and B) (Carlton et al. 2007) at $55^{\circ} \mathrm{C}$, a $2 \mathrm{~min}$ extension step at $72^{\circ} \mathrm{C}$ for 30 cycles and a $5 \mathrm{~min}$ 
TABLE

Polymerase chain reaction (PCR) primer design

\begin{tabular}{|c|c|c|c|c|}
\hline Enzyme & $\begin{array}{l}\text { Primer sequences } \\
\qquad\left(5^{\prime} \rightarrow 3^{\prime}\right)\end{array}$ & $\begin{array}{l}\text { Annealing temperature } \\
\qquad\left({ }^{\circ} \mathrm{C}\right)\end{array}$ & $\begin{array}{l}\text { PCR product } \\
\text { (bp) }\end{array}$ & $\begin{array}{l}\text { GenBank accession } \\
\text { (mRNA) }\end{array}$ \\
\hline NTPDase A & $\begin{array}{l}\text { F-TGAAGAAGAGTTGAAGGGCAAAG } \\
\text { R-AATTCTTCGACAGGAGGCATTG }\end{array}$ & 53 & 342 & XM_001298945 \\
\hline NTPDase B & $\begin{array}{l}\text { F-CGACTACATCATCTCTTGCCGATC } \\
\text { R-GACTCTCTTATGTATCTTTGGGCAG }\end{array}$ & 53 & 397 & XM_001579653 \\
\hline$\alpha$-tubulin & $\begin{array}{c}\text { F-GCCAACATGATGGTTAAGTGCGATCCAC } \\
\text { R-CAGCTTCTTCCATACCCTCACCGACG }\end{array}$ & 61 & 355 & XM_001330630 \\
\hline
\end{tabular}

mRNA: messenger ribonucleic acid; NTPDase: nucleoside triphosphate diphosphohydrolase.

final extension at $72^{\circ} \mathrm{C}$. Negative controls were included for each PCR set. The PCR products were separated on a $1 \%$ agarose gel using $10 \mathrm{x}$ GelRed (Invitrogen, Carlsbad, CA, USA) and visualised with ultraviolet light. The band intensities were analysed by densitometry using the freeware ImageJ 1.37 software for Windows. The $\alpha$-tubulin gene was used to normalise the PCR products in a single gel. The results are representative of at least three independent experiments (using different cultures).

Analysis of extracellular ATP metabolism by high performance liquid chromatography (HPLC) - Following the serum-limited incubation period, $T$. vaginalis trophozoites were harvested and washed three times with $0.9 \%(\mathrm{w} / \mathrm{v}) \mathrm{NaCl}$ solution. The parasite suspensions were diluted to a final protein concentration of approximately $0.6 \mathrm{mg} / \mathrm{mL}$ (ATCC 30236 isolate) and $0.4 \mathrm{mg} / \mathrm{mL}$ (TVLACH1 isolate). The total protein content was measured using the Coomassie blue method. Intact organisms were added to the reaction mixture $(50 \mathrm{mM}$ Tris buffer, $\mathrm{pH} 7.2$ and $5.0 \mathrm{mM} \mathrm{CaCl}_{2}$ ) and the reaction was initiated with the addition of $0.5 \mathrm{mM}$ ATP (final concentration) at $37^{\circ} \mathrm{C}$. After the designated incubation time $(0,5,10,30,60$ or $90 \mathrm{~min}$ ), the reactions were stopped and placed on ice. The incubation medium was centrifuged at $11,000 \mathrm{~g}$ for $10 \mathrm{~min}$. Aliquots of $20 \mu \mathrm{L}$ were injected in the chromatographic system (LC-20AT Prominence Liquid Chromatograph, Shimadzu) and the data were acquired using the LC Solution Software (Shimadzu). The chromatographic separation was performed in a Luna C18(2) column (150 $\mathrm{mm} \times 4.6 \mathrm{~mm}, 3 \mu \mathrm{m}$, Phenomenex, Torrance, CA) and a pre-column $(4.0 \mathrm{~mm} \times 3.0 \mathrm{~mm}, 3 \mu \mathrm{m})$ using $20 \mathrm{mM}$ $\mathrm{KH}_{2} \mathrm{PO}_{4}$ and $40 \mathrm{mM} \mathrm{K}_{2} \mathrm{HPO}_{4}(\mathrm{pH}$ 7.0) solutions as mobile phase $\mathrm{A}$ and acetonitrile as mobile phase B. Buffer solutions were filtered through a $0.45 \mu \mathrm{m}$ membrane pore (Millipore, Bedford, USA). The mobile phase was eluted at a flow rate of $0.8 \mathrm{~mL} / \mathrm{min}$ along the gradient that was proposed by Vallé et al. (1998). The analyte was detected at $260 \mathrm{~nm}$. All of the peaks were identified by retention time and a comparison with the standards. The controls to correct for the non-enzymatic hydrolysis of nucleotides were performed by measuring the peaks from the same reaction medium that was incubated without trophozoites. The controls for cellular purine secretion were performed by incubating the parasites without the substrate under the identical culture conditions described above.
The results are representative of two independent experiments (using different cultures).

Cell cycle analysis by flow cytometry - For the flow cytometry analysis, both isolates were maintained in TYM medium supplemented with $1 \%(\mathrm{v} / \mathrm{v})$ HIBS for $2 \mathrm{~h}$ to allow for a comparison of the cell cycle between the isolates. Inocula of $5.0 \times 10^{5}$ trophozoites $/ \mathrm{mL}$ were incubated under either normal or serum-limiting conditions and were harvested and washed three times with PBS. The cells were then fixed with $70 \%$ cold ethanol at $4^{\circ} \mathrm{C}$ for $45 \mathrm{~min}$. The trophozoites were incubated with $100 \mu \mathrm{g} / \mathrm{mL}$ RNase A at $37^{\circ} \mathrm{C}$ for $15 \mathrm{~min}$ and then stained with $50 \mu \mathrm{g} / \mathrm{mL}$ propidium iodide (Sigma) at room temperature in the dark for $30 \mathrm{~min}$. The cell cycle was analysed using a FACSCalibur flow cytometer (BD Biosciences). Following the acquisition of 50,000 events, the data were analysed using FlowJo software (Tree Star). The results are representative of at least three independent experiments (using different cultures).

Statistical analysis - The statistical analysis was conducted using the Student's $t$ test and a 5\% level of significance was applied to the data.

\section{RESULTS}

In this study, we evaluated the effects of a serumlimiting condition on the levels of ATP, ADP and AMP hydrolysis in $T$. vaginalis trophozoites. Cellular integrity and viability were assessed before and after the enzymatic assays by examining the motility and the viability of the trophozoites with trypan blue exclusion. The integrity of the trophozoites was not affected by any of the culture conditions. Furthermore, to investigate the effects of bovine serum limitation on the growth and morphology of $T$. vaginalis, kinetic growth experiments were performed. As shown in Fig. 1, the in vitro growth of the trichomonads was affected by serum limitation (1\% HIBS) compared with the control cultures (10\% HIBS). The viability of the 30236 isolate decreased by $55 \%$ (Fig. 1A) and the live parasites demonstrated reduced motility and a round morphology after $4 \mathrm{~h}$ in a serum-limiting condition. The growth of the TV-LACH1 isolate remained similar to that of the control until $24 \mathrm{~h}$ of incubation, at which point the TV-LACH1 isolate exhibited a significant reduction in growth (Fig. 1B). Based on these findings, we subse- 
quently chose to use 2-h and 24-h incubations for the 30236 and TV-LACH1 isolates, respectively.

Next, the effects of bovine serum limitation on the NTPDase and ecto-5'-nucleotidase activities were evaluated. The experimental conditions promoted significant increases in the hydrolysis rates of both isolates, as shown in Fig. 2. The 30236 isolate showed heightened enzymatic activation, as the rates of ATP, ADP and AMP hydrolysis increased $154.4 \%, 176.1 \%$ and $302.5 \%$, respectively, compared to the control cultures (Fig. 2A). The TV-LACH1 clinical isolate also had increased rates of ATP, ADP and AMP hydrolysis at $14.4 \%, 22.5 \%$ and $162.5 \%$, respectively (Fig. 2B). The hydrolysis of AMP was greater than that of the nucleoside tri and diphosphates in both isolates. Furthermore, the clinical isolate (TV-LACH1) displayed greater enzymatic activities than did the representative long-term culture isolate (ATCC 30236).

Semiquantitative RT-PCR experiments were performed to verify that bovine serum limitation could influence gene expression of the enzymes responsible for extracellular nucleotide hydrolysis. To investigate the effects of serum limitation on NTPDase transcriptional control, we evaluated the gene expression of two NTPDase sequences obtained from the $T$. vaginalis genome (the sequence of NTPDase A was 434 amino acids long and the sequence of NTPDase B was 441 amino acids long). Both of these sequences contained the five characteristic apyrase conserved regions of the NTPDase family. The comparison of gene expression from cells in different experimental conditions was performed using band densitometry and the calculation of the enzyme/ $\alpha$-tubulin ratio. The results indicated that the serumlimiting condition tested altered the NTPDase A and B transcript levels in T. vaginalis (Fig. 3). For the 30236
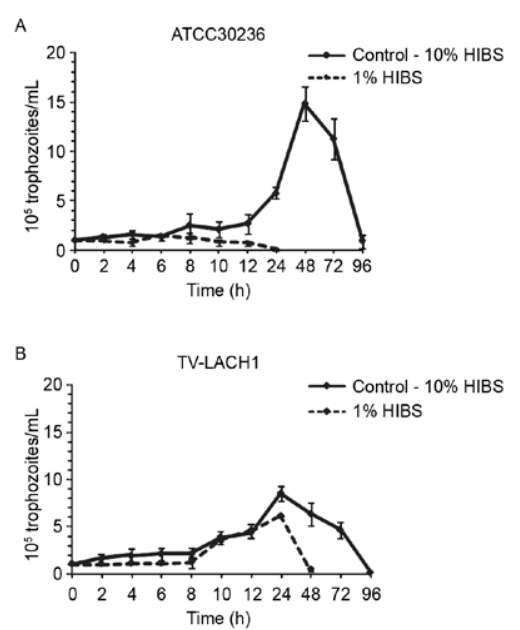

Fig. 1: effect of bovine serum limitation [1\% heat-inactivated bovine serum (HIBS)] on Trichomonas vaginalis kinetic growth curve. A: effect of an initial inoculum at $1.0 \times 10^{5}$ trophozoites $/ \mathrm{mL}$ in long-termgrown isolate (ATCC 30236) showing an important growth reduction in the first hours when trichomonads were cultivated on $1 \%$ HIBS; B: for the clinical isolate (TV-LACH1), the growth remained similar to control until $24 \mathrm{~h}$ of incubation. Bars represent the mean \pm standard deviation of at least three experiments, each in triplicate. isolate, the expression of the NTPDase A transcript was increased in comparison to the control culture. However, this was not seen for the NTPDase B transcript, as the NTPDase/ $\alpha$-tubulin ratio was no different than the control (Fig. 3A). For the TV-LACH1 isolate, serum limitation promoted greater gene expression of both the NTPDase A and B enzymes (Fig. 3B).

To gain a better understanding of the extracellular adenine nucleotide hydrolysis, we investigated the ATP metabolism of $T$. vaginalis trophozoites following HIBS limitation over a period of $90 \mathrm{~min}$ by HPLC. For the 30236 isolate (Fig. 4), we observed that the ATP consumption in the test culture was faster (Fig. 4C) than in the control culture (Fig. 4A), which was in agreement with the increased ATP hydrolysis (Fig. 2A). The decrease in ATP concentration was followed by increased formation of ADP and AMP in the trophozoites maintained in 1\% serum than in those grown in $10 \%$ serum. On the other hand, the change in the adenosine concentration had a distinct profile; the nucleoside was completely consumed in the control culture in the first $30 \mathrm{~min}$ and began to accumulate after this period (Fig. 4B), while the adenosine was fully consumed in the treated trophozoite culture over a period of $90 \mathrm{~min}$ (Fig. 4D). This suggested that the parasites maintained in $1 \%$ HIBS exhibited a greater adenosine dependence than the control culture.

The adenine nucleotide metabolism in the TVLACH1 isolate is shown in Fig. 5. In the control culture, ATP was moderately metabolised and there was subsequent ADP and AMP formation (Fig. 5A). Adenosine was produced within the first $10 \mathrm{~min}$ and had been consumed at the next time point analysed (Fig. 5B). From these tests, we observed that ATP hydrolysis began dur-
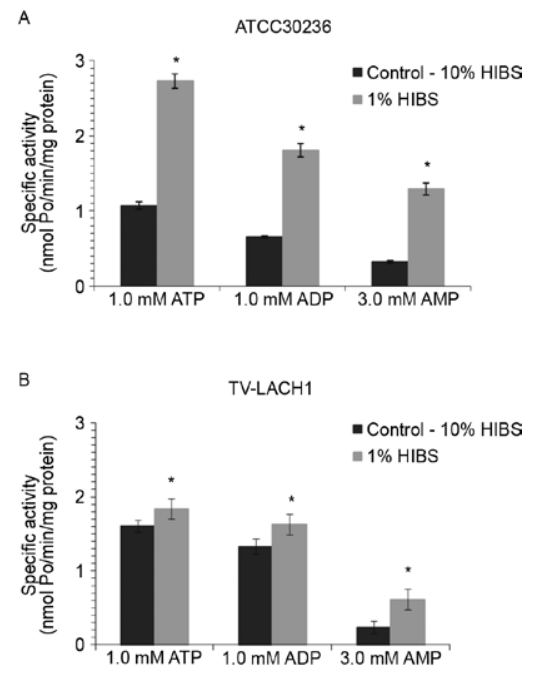

Fig. 2: effect of bovine serum limitation $[1 \%$ heat-inactivated bovine serum (HIBS)] on nucleoside triphosphate diphosphohydrolase (NTPDase) and ecto-5'-nucleotidase activities in Trichomonas vaginalis. Serum limitation promoted a significant increase of ATP, ADP and AMP hydrolysis in ATCC 30236 (A) and TV-LACH1 isolates (B). Bars represent the mean \pm standard deviation of at least three experiments, each in triplicate. Asterisk means significant difference from controls by the Student's $t$ test $(\mathrm{p}<0.05)$. Pi: inorganic phosphate. 
ing the first minutes in culture and that this compound was increasingly consumed over time. Thus, the ADP and AMP products of the enzymatic reaction were increasing generated over time (Fig. 5C). Adenosine, the product from the last step in the extracellular ATP cascade, was initially produced and subsequently consumed until it was completely depleted (Fig. 5D).

As serum deprivation can alter the cell cycle (Chou \& Langan 2003, Gos et al. 2005, Krzeminski et al. 2007) and increase the pool of adenine nucleotides (Rapaport $\&$ Zamecnik 1978) in a variety of cell types, we investigated the effect of HIBS limitation on the T. vaginalis cell cycle. The results demonstrated that serum limitation caused an arrest of the T. vaginalis cell cycle. In regards to the 30236 isolate, the percentage of cells in the G0/G1, S and G2 stages changed from $26.49 \%, 50.79 \%$ and $22.58 \%$ to $52.51 \%, 30.69 \%$ and $16.28 \%$, respectively, in response to serum limitation (Fig. 6). Likewise, the TV-LACH1 parasites exhibited a significant arrest in cell cycle at the G0/G1 phase (45.69-67.13\%) and the percentages of cells in the S and G2 stages changed from $36.32 \%$ and $21 \%$ to $20.89 \%$ and $13.59 \%$, respectively, following serum limitation (Fig. 6).

\section{DISCUSSION}

The current report is the first to evaluate the influence of bovine serum limitation on extracellular nucleotide hydrolysis/metabolism and enzyme gene expression of T. vaginalis trophozoites. In response to incubation in a medium with 1\% serum, the ATCC 30236 isolate (longterm-cultured parasite) demonstrated a more pronounced sensitivity towards this stressful condition than the fresh clinical isolate (TV-LACH1). These differences are most likely due to the heterogeneity of these long-term-cultured and the fresh clinical isolates, which resulted in diverse kinetic growth profiles and sensitivity to serum limitation. The ability of $T$. vaginalis to adapt to a challenging environmental pressure may be explained by the trichomonads possessing signal transduction pathways that link changes in the environment to appropriate changes in transcriptional and post-transcriptional regulatory mechanisms (Lehker \& Alderete 2000). Furthermore, virulence factors of $T$. vaginalis clinical isolates, such as the adhesion to epithelial cells, morphologic transformations, cytotoxicity and phagocytosis, are strongly reduced when the parasites are submitted to continuous and prolonged in vitro culture (Arroyo et al. 1992, Gilbert et al. 2000, Cuervo et al. 2008). These data highlight the differences between isolates and explain the distinct serum limitation susceptibility profiles observed.

Our results demonstrated that bovine serum limitation promoted a significant increase in the extracellular hydrolysis of ATP, ADP and AMP. In response to serum limitation, the NTPDase and ecto-5'-nucleotidase activities were enhanced and the AMP hydrolysis rates of both isolates were greater than that of the other nucleotides. This dramatic increase in AMP hydrolysis, which is the step in the enzymatic pathway responsible for the production of adenosine, was in agreement with our working hypothesis that had proposed that reduced serum concentrations would result in the activation of ectonucleotidases. Gottlieb (1985) showed that the levels of the 3'- and 5'-nucleotidase activities in the trypanosomatid Crithidia fasciculata were regulated by the availability of adenosine in the culture medium. Specifically, the organisms grown in purine-depleted culture medium had elevated enzyme activity levels over those grown in complete medium. Our findings corroborate these data and strongly suggest that these enzymes play a fundamental role in the generation of adenosine, which is essential for the growth and metabolism of the parasites (Munagala \& Wang 2003). The results obtained from the HPLC analysis are also in agreement with this idea, as the serum-limited cultures had a greater ability to hydrolyse ATP and to consume adenosine. Therefore, we hypothesised that the low concentrations of adenosine depicted in Figs 4, 5, as well as the reduction in the nucleoside level after a certain period in culture, may have been the result of rapid adenosine uptake. Harris et al. (1988) demonstrated that T. vaginalis trophozoites can re-uptake adenosine rapidly, within $100 \mathrm{sec}$. Moreover, adenosine is transported at a faster rate than guanosine, but at a substantially more rapid rate than uridine. Notably, the study by Harris et al. (1988) found that approximately $75 \%$ of the adenosine recovered after $10 \mathrm{sec}$ was within the nucleotide fraction and was principally in the form of ADP and ATP. In this context, further studies are required to clarify the pathway followed by the adenosine produced by ATP metabolism under a condition of serum limitation.

The RT-PCR analysis demonstrated that serum reduction promoted an increase in the relative gene expression of the NTPDase A and B transcripts in both isolates. Increased messenger ribonucleic acid levels were observed in the TV-LACH1 isolates than in the 30236 isolates. This difference may be attributed to the time that the cultures were exposed to the condition tested, as the clinical isolate (TV-LACH1) trophozoites were maintained for $24 \mathrm{~h}$ in a medium with $1 \%$ serum and the

A

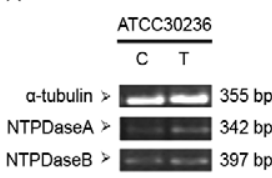

B
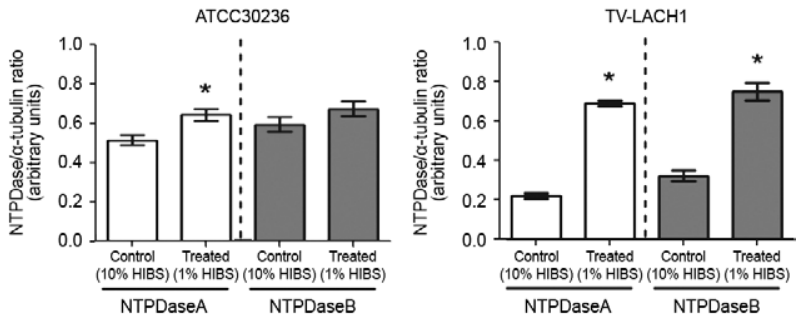

Fig. 3: gene expression patterns of nucleoside triphosphate diphosphohydrolase (NTPDase) members after bovine serum limitation $[1 \%$ heat-inactivated bovine serum (HIBS)]. A: on ATCC 30236 was observed only an increase on the expression of NTPDase A; B: for TV$\mathrm{LACH} 1$ isolate, the serum limitation promoted higher gene expression levels of both NTPDase A and B enzymes. Bars represent the mean \pm standard deviation of at least three experiments. Asterisk means significant difference from controls by the Student's $t$ test $(\mathrm{p}<0.05)$. 

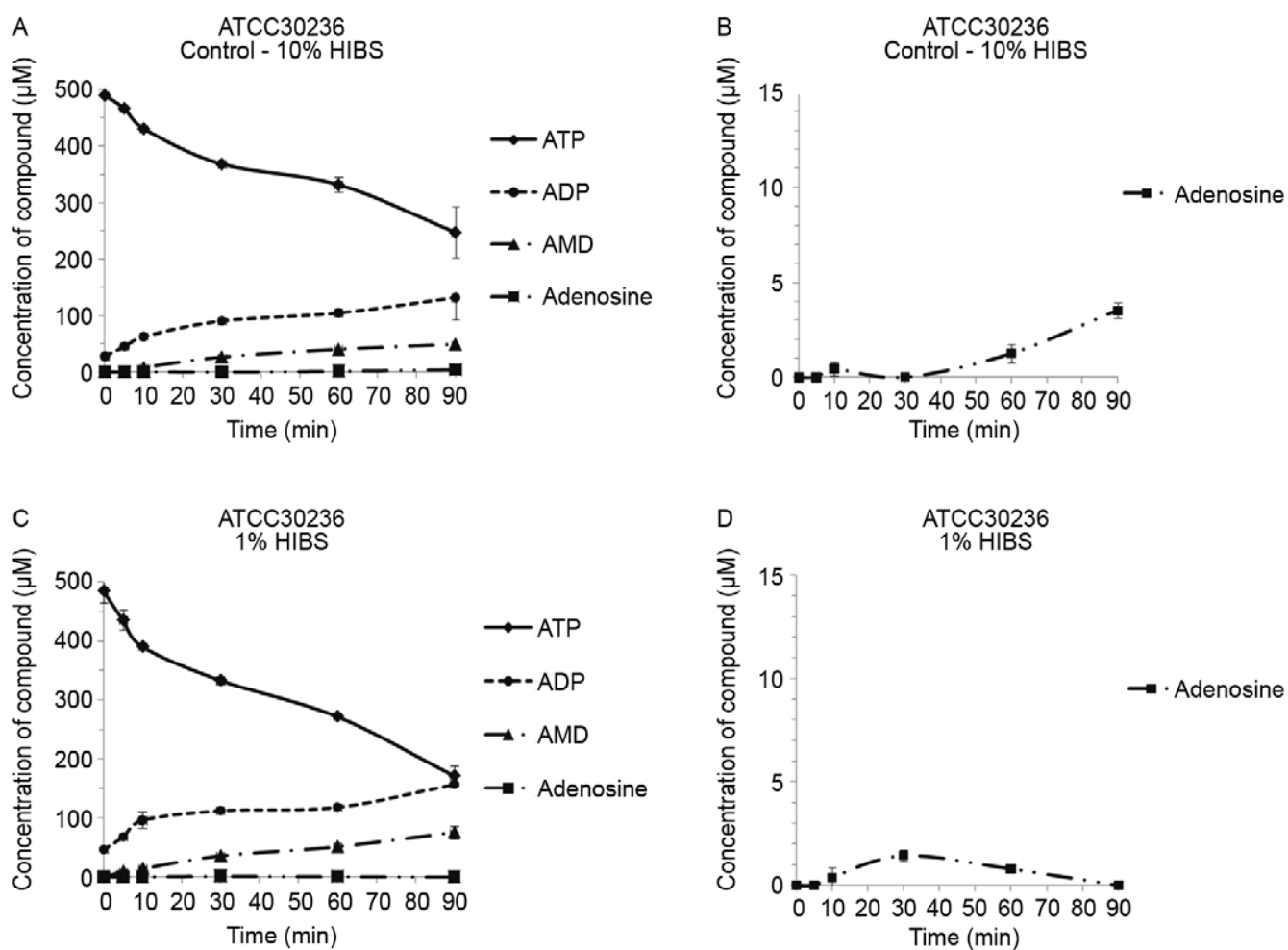

Fig. 4: ATP hydrolysis and product formation by Trichomonas vaginalis (ATCC 30236) after bovine serum limitation $[1 \%$ heat-inactivated bovine serum (HIBS)]. A: control (10\% HIBS); B: amplification of adenosine formation; C: cells maintained on 1\% HIBS; D: amplification of adenosine formation. Bars represent the mean \pm standard deviation of at least two experiments.
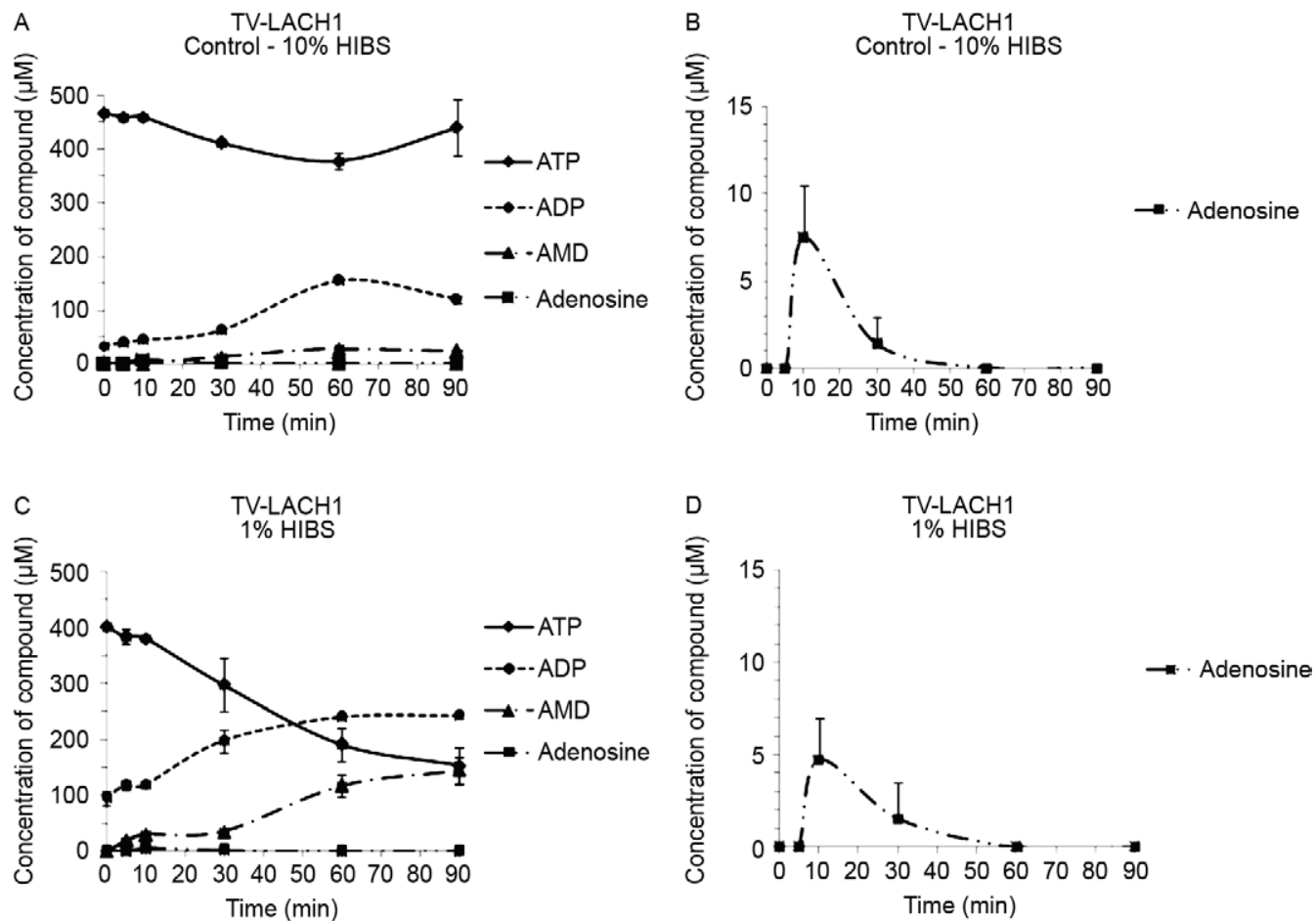

Fig. 5: ATP hydrolysis and product formation by Trichomonas vaginalis (TV-LACH1) after bovine serum limitation [1\% heat-inactivated bovine serum (HIBS)]. A: control (10\% HIBS); B: amplification of adenosine formation; C: cells maintained on 1\% HIBS; D: amplification of adenosine generation. Bars represent the mean \pm standard deviation of at least two experiments. 
30236 isolate was maintained under these conditions for only $2 \mathrm{~h}$. This short incubation may have resulted in the lack of evident gene upregulation.

In contrast and despite an exhaustive search, the GenBank databases did not reveal the existence of any putative $T$. vaginalis homologues for the ecto-5'-nucleotidase (Carlton et al. 2007). This may be explained by the occurrence of error rates during the functional assignment of these enzymes and by these estimates can ranging from $5-40 \%$, depending on the definition of "function". Moreover, in terms of the accuracy and utility of a functional annotation, it is important to consider that an enzyme can have different functions, depending on its temporal and spatial expression within the cell. The concept that each enzyme has only one function is overly simplistic and this promiscuity raises several issues for the functional annotation, as each function should be qualified by its cellular context (Furnham et al. 2009).

In the vaginal environment, the nutritional requirements of the parasites are provided by the epithelial cells, leukocytes and other microorganisms, which are phagocytosed by trichomonads (Pereira-Neves \& Benchimol 2007). During a menstrual cycle, erythrocytes provide additional nutrient sources including nucleotides, lipids, haemin and haemoglobin, which are compounds that sustain T. vaginalis growth (Lehker et al. 1990, Alderete et al. 2004). For trichomonad culture in vitro, the serum added to the growth medium is extremely important for trophozoite growth maintenance. The main role of the serum is to supply lipids, in particular fatty acids and cholesterol, in a form that can be assimilated by the organism without toxicity (Linstead 1990). However, besides these compounds, serum provides additional molecules that are essential for the parasites, such as precursors of the purine and pyrimidine nucleotides (Wang et al. 1984). Adenosine is used by the parasite for nucleic acid synthesis, ATP generation and intracellular signalling and the ectonucleotidases represent an efficient pathway for the acquisition of adenosine. As T. vaginalis lacks de novo purine synthesis, these enzymes play an important role in adenosine production, which is necessary for the survival of the parasite (Munagala \& Wang 2003).

In this study, serum limitation promoted the activation of NTPDase and ecto-5'-nucleotidase activities, which indicated that these enzymes are used to produce adenosine that will be uptake by the purine salvage pathways in this culture condition. Similarly, previous studies have shown that the incorporation of adenosine into ATP and ADP pools is markedly increased in serum-deprived mammalian cells (Rapaport \& Zamecnik 1978, Albert \& Gudast 1985). Importantly, serum deprivation is a well-established process that promotes cell cycle arrest at the $\mathrm{G} 0$ / G1 stage in several cell types (Kues et al. 2000, Cooper 2003) and this was further supported in the present study. Thus, according to a study by Rapaport and Zamecnik (1978), the increased incorporation of adenosine into the nucleotide pools driven by serum limitation may act as a signal that mediates an intracellular response to environmental changes and halts cellular proliferation.

In summary, the present report has demonstrated the important role of ectonucleotidases and specifically the

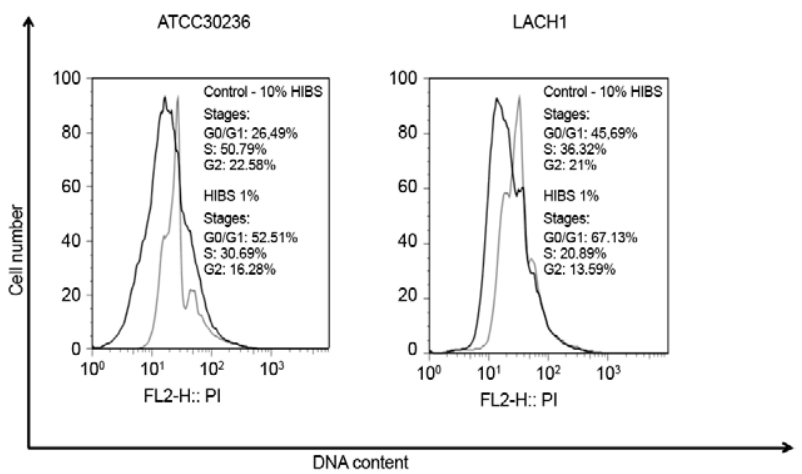

Fig. 6: effect of bovine serum limitation [1\% heat-inactivated bovine serum (HIBS)] on cell cycle stages in Trichomonas vaginalis. The cell cycle arrest at G0/G1 phase was observed for the ATCC 30236 and TVLACH1 isolates after serum limitation. Control is represented by gray lines and test by black lines. The data are representative of at least three independent experiments. FL2-H-PI: propidium iodide fluorescence.

NTPDase and the ecto-5'-nucleotidase, in the production of adenosine by $T$. vaginalis trophozoites in conditions of serum limitation. Furthermore, these results emphasise the relevance of the enzymatic pathway that breaks down ATP and provides adenosine for parasite growth to support the establishment of the infection. Future investigations using an RNA interference approach will further contribute to understanding of the role of NTPDase and ecto-5'-nucleotidase activities in $T$. vaginalis biology, as well as to searching their potential use as pharmacological targets.

\section{REFERENCES}

Albert DA, Gudast LJ 1985. Ribonucleotide reductase activity and deoxyribonucleoside triphosphate metabolism during the cell cycle of S49 wild-type and mutant mouse T-lymphoma cells. J Biol Chem 26: 679-684.

Alderete JF, Nguyen J, Mundodi V, Lehker MW 2004. Heme-iron increases levels of AP65-mediated adherence by Trichomonas vaginalis. Microb Pathog 36: 263-271.

Arroyo R, Engbring J, Alderete JF 1992. Molecular basis of host epithelial cell recognition by Trichomonas vaginalis. Mol Microbiol 6: 853-862.

Bradford MM 1976. A rapid and sensitive method for the quantification of microgram quantities of protein utilizing the principle of protein-dye binding. Anal Biochem 72: 218-254.

Burnstock G 2007. Physiology and pathophysiology of purinergic neurotransmission. Physiol Rev 87: 659-797.

Carlton JM, Hirt RP, Silva JC, Delcher AL, Schatz M, Zhao Q, Wortman JR, Bidwell SL, Alsmark UC, Besteiro S, Sicheritz-Ponten T, Noel CJ, Dacks JB, Foster PG, Simillion C, Van de Peer Y, Miranda-Saavedra D, Barton GJ, Westrop GD, Müller S, Dessi D, Fiori PL, Ren Q, Paulsen I, Zhang H, Bastida-Corcuera FD, Simoes-Barbosa A, Brown MT, Hayes RD, Mukherjee M, Okumura CY, Schneider R, Smith AJ, Vanacova S, Villalvazo M, Haas BJ, Pertea M, Feldblyum TV, Utterback TR, Shu CL, Osoegawa K, de Jong PJ, Hrdy I, Horvathova L, Zubacova Z, Dolezal P, Malik SB, Logsdon JM Jr, Henze K, Gupta A, Wang CC, Dunne RL, Upcroft JA, Upcroft P, White O, Salzberg SL, Tang P, Chiu $\mathrm{CH}$, Lee YS, Embley TM, Coombs GH, Mottram JC, Tachezy J, Fraser-Liggett CM, Johnson PJ 2007. Draft genome sequence 
of the sexually transmitted pathogen Trichomonas vaginalis. Science 315: 207-212.

Chan KM, Delfert D, Junger KD 1986. A direct colorimetric assay for $\mathrm{Ca}^{2+}$-stimulated ATPase activity. Anal Biochem 157: 375-380.

Cherpes T, Wiesenfeld H, Melan M, Kant JA, Consentino LA, Meyn LA, Hillier SL 2006. The associations between pelvic inflammatory disease, Trichomonas vaginalis infection, and positive herpes simplex virus type 2 serology. Sex Transm Dis 33: 747-752.

Chou RC, Langan TJ 2003. In vitro synchronization of mammalian astrocytic cultures by serum deprivation. Brain Res Brain Res Protoc 11: 162-167.

Cooper S 2003. Reappraisal of serum starvation, the restriction point G0 and G1 phase arrest points. FASEB J 17: 333-340.

Cotch MF, Pastorek JG, Nugent RP, Hillier SL, Gibbs RS, Martin DH, Eschenbach DA, Eldeman R, Carey JC, Regan JA, Krohn MA, Klebanoff MA, Rao AV, Rhoads GG 1997. Trichomonas vaginalis associated with low birth weight and preterm delivery. The Vaginal Infections and Prematurity Study Group. Sex Transm Dis 24: $353-360$

Cuervo P, Cupolillo E, Britto C, González LJ, E Silva-Filho FC, Lopes LC, Domont GB, De Jesus JB 2008. Differential soluble protein expression between Trichomonas vaginalis isolates exhibiting low and high virulence phenotypes. J Proteomics 71: 109-122.

Diamond LS 1957. The establishment of various Trichomonas of animals and man in axenic cultures. $J$ Parasitol 43: 488-490.

Furnham N, Garavelli JS, Apweiler R, Thornton JM 2009. Missing in action: enzyme functional annotations in biological databases. Nat Chem Biol 5: 521-525.

Gilbert RO, Elia G, Beach DH, Klaessig S, Singh BN 2000. Cytopathogenic effect of Trichomonas vaginalis on human vaginal epithelial cells cultured in vitro. Infect Immun 68: 4200-4206.

Giordani RB, Weizenmann M, Rosemberg DB, De Carli GA, Bogo MR, Zuanazzi JA, Tasca T 2010. Trichomonas vaginalis nucleoside triphosphate diphosphohydrolase and ecto-5'-nucleotidase activities are inhibited by lycorine and candimine. Parasitol Int 59: 226-231

Goldstein F, Goldman MB, Cramer DW 1993. Relation of tubal infertility to story of sexually transmitted diseases. Am J Epidem 137: 577-584.

Gos M, Miloszewska J, Swoboda P, Trembacz H, Skierski J, Janik P 2005. Cellular quiescence induced by contact inhibition or serum withdrawal in C3H10T1/2 cells. Cell Prolif 38: 107-116.

Gottlieb M 1985. Enzyme regulation in a trypanosomatid: effect of purine starvation on levels of 3'-nucleotidase activity. Science 227: $72-74$.

Harris DI, Beechey RB, Linstead D, Barret J 1988. Nucleoside uptake by Trichomonas vaginalis. Mol Biochem Parasitol 29: 105-116.

Heyworth PG, Gutteridge WE, Ginger CD 1982. Purine metabolism in Trichomonas vaginalis. FEBS Let 14: 106-110.

Johnston VJ, Mabey DC 2008. Global epidemiology and control of Trichomonas vaginalis. Curr Opin Infect Dis 21: 56-64.

Krzeminski P, Supłat D, Czajkowski R, Pomorski P, Baranska P 2007. Expression and functional characterization of $\mathrm{P} 2 \mathrm{Y} 1$ and $\mathrm{P} 2 \mathrm{Y} 12$ nucleotide receptors in long-term serum-deprived glioma C6 cells. FEBS J 274: 1970-1982.

Kucknoor AS, Mundodi V, Alderete JF 2005. Heterologous expression in Tritrichomonas foetus of functional Trichomonas vaginalis AP65 adhesin. BMC Mol Biol 6: 5.

Kues WA, Anger M, Carnwath JW, Paul D, Motlik J, Niemann H 2000. Cell cycle synchronization of porcine fetal fibroblasts: ef- fects of serum deprivation and reversible cell cycle inhibitors. Biol Reprod 62: 412-419.

Lehker MW, Alderete JF 2000. Biology of trichomonosis. Curr Opin Infect Dis 13: 37-45.

Lehker MW, Chang T-H, Dailey DC, Alderete JF 1990. Specific erythrocyte binding is an additional nutrient acquisition system for Trichomonas vaginalis. J Exp Med 171: 2165-2170.

Linstead D 1990. Cultivation. In BM Honigberg, Trichomonads parasitic in humans, Springer, New York, p. 5-35.

Matos JAA, Borges FP, Tasca T, Bogo MR, De Carli GA, Fauth MG, Dias RD, Bonan CD 2001. Characterization of an ATP diphosphohydrolase (apyrase, EC 3.6.1.5) activity in Trichomonas vaginalis. Int J Parasitol 31: 770-775.

Munagala NR, Wang CC 2003. Adenosine is the primary precursor of all purine nucleotides in Trichomonas vaginalis. Mol Biochem Parasitol 127: 143-149.

Pereira-Neves A, Benchimol M 2007. Phagocytosis by Trichomonas vaginalis: new insights. Biol Cell 99: 87-101.

Rapaport E, Zamecnik PC 1978. Increased incorporation of adenosine into adenosine nucleotide pools in serum-deprived mammalian cells. Proc Natl Acad Sci USA 75: 1145-1147.

Robson SC, Sévigny J, Zimmermann H 2006. The E-NTPDase family of ectonucleotidases: structure function relationships and pathophysiological significance. Purinergic Signal 2: 409-430.

Rückert C, Stuepp CS, Gottardi B, Rosa J, Cisilotto J, Borges FP, Rosemberg DB, Bogo MR, Tasca T, De Carli GA, Bonan CD 2010. Trichomonas vaginalis: dehydroepiandrosterone sulfate and 17 beta-estradiol alter NTPDase activity and gene expression. Exp Parasitol 125: 187-195.

Sansom FM, Robson SC, Hartland EL 2008. Possible effects of microbial ecto-nucleoside triphosphate diphosphohydrolases on host-pathogen interactions. Microbiol Mol Biol Rev 72: 765-781.

Tasca T, Bonan CD, De Carli GA, Battastini AMO, Sarkis JJF 2003. Characterization of an ecto-5'-nucleotidase (EC 3.1.3.5) activity in intact cells of Trichomonas vaginalis. Exp Parasitol 105: 167-173.

Tasca T, Bonan CD, De Carli GA, Sarkis JJ, Alderete JF 2005. Heterogeneity in extracellular nucleotide hydrolysis among clinical isolates of Trichomonas vaginalis. Parasitology 131: 71-78.

Vallé M, Malle P, Bouquelet S 1998. Evaluation of fish decomposition by liquid chromatographic assay of ATP degradation products. J AOAC Int 81: 571-575.

Van Der Pol B, Kwok C, Pierre-Louis B, Rinaldi A, Salata RA, Chen PL, Van De Wijgert J, Miro F, Mugerwa R, Chipato T, Morrison CS 2008. Trichomonas vaginalis infection and human immunodeficiency virus acquisition in African women. $J$ Infect Dis 197: 548-554.

Viikki M, Pukkala E, Nieminen P, Hakama M 2000. Gynecological infections as risk determinants of subsequent cervical neoplasia. Acta Oncol (Madr) 39: 71-75.

Wang CC, Wang AL, Rice A 1984. Tritrichomonas foetus: partly defined cultivation medium for study of the purine and pyrimidine metabolism. Exp Parasitol 57: 68-75.

WHO - World Health Organization 2001. Global prevalence and incidence of selected curable sexually transmitted infections. Overview and estimates, WHO, Geneva, $42 \mathrm{pp}$.

Yegutkin GG 2008. Nucleotide- and nucleoside-converting ectoenzymes: important modulators of purinergic signalling cascade. Biochim Biophys Acta 1783: 673-694.

Zimmermann H 2001. Ectonucleotidases: Some recent developments and a note on nomenclature. Drug Dev Res 52: 44-56. 